\title{
MODIFIED EDGE FED SIERPINSKI CARPET MINIATURIZED MICROSTRIP PATCH ANTENNA
}

\author{
0. S. Zakariyya ${ }^{1,}{ }^{*}$, B. O. Sadiq ${ }^{2}$, O. A. Abdulrahman ${ }^{3}$ and A. F. Salami ${ }^{4}$ \\ 1 DEPARTMENT OF ELECTRICAL AND ELECTRONICS ENGINEERING, UNIVERSITY OF ILORIN, ILORIN. KWARA STATE. NIGERIA

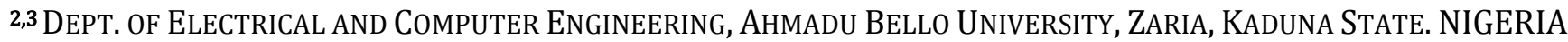 \\ 4 DEPARTMENT OF COMPUTER ENGINEERING, UNIVERSITY OF ILORIN, ILORIN. KWARA STATE. NIGERIA \\ Email addresses:12zakariyya.os@unilorin.edu.ng, ${ }^{2}$ bosadiq@abu.edu.ng,3olaniyanabdulrahman@gmail.com, \\ ${ }^{4}$ salami.af@unilorin.edu.ng.
}

\begin{abstract}
This paper presented a modified edge fed Sierpinski carpet microstrip patch antenna for antenna miniaturization. The proposed design was etched as Sierpinski carpet to lower the antenna resonant frequency, which is used to reduce the conventional patch antenna size. After the Sierpinski carpet second iteration, the proposed antenna was modified by replacing the rectangular slot in the middle of the patch with a circular slot. Simulation results showed that the proposed antenna achieved $46.5 \%$ size reduction when compared with the main patch antenna without affecting the resonant frequency and radiation patterns.
\end{abstract}

Keywords: Microstrip patch antenna, fractal antenna, Miniaturization, Sierpinski Carpet.

\section{INTRODUCTION}

One of the essential elements for the remarkable growth recorded by wireless communication is the antenna. Antenna plays a vital role in a communications system as signal reception and transmission cannot be carried out without the use of an antenna. Low cost and portable devices are in demand presently, to achieve these miniaturized communication devices, antenna size must be reduced and light in weight. The advantage presented by microstrip patch antenna such as light weight, low cost and easy integration with circuitry devices makes them the suitable choice for the present day wireless communication device demands. Several methods have been proposed for reducing the size of microstrip patch antenna which includes applying shorting techniques [1], increasing the length of the antenna by optimizing its shape [2] and using high dielectric [3]. It was reported in [4] that the size of an edge fed microstrip patch antenna can be reduced mainly by two techniques which are inserting capacitive element into the patch and loading the patch edges with inductive element. Recently, fractal geometries have been introduced in the design of microstrip antenna for miniaturization purposes.
Fractals in 1975 were defined as a way of classifying structures whose dimensions were not whole numbers by Benoit Mandelbrot. Fractal shapes usually consist of copies of themselves but with different scales, and have no specific size. Among various types of fractal geometries, the most common ones employed in antenna design includes Sierpinski carpet [5, 6], Sierpinski Gasket [7], Minkowski loop [8] and Koch curve [9]. Compact circularly polarized rectenna with unbalanced circular slots was proposed by Y.O et al. $12 \%$ size reduction was achieved by reducing the radius of rectenna from $16.5 \mathrm{~mm}$ to $15.5 \mathrm{~mm}$ [10]. By using the asymmetric slit to reduce the size of a square patch antenna, $40 \%$ size reduction was achieved [11]. The Surface of patch antenna was etched with a cross shape slot to achieve $32.5 \%$ size reduction in [12]. The Combination of bowtie and fractal shape was employed in [13] to reduce antenna size but the proposed antenna radiation characteristics were greatly affected. An inductive loading size reduction technique using Koch curve geometry was proposed in [14] to reduce the size of microstrip patch antenna. A small size microstrip patch antenna fed at the edge for miniaturization was proposed in [15].The antenna achieves $17 \%$ size 
reduction after the third iteration of the Sierpinski carpet fractal. A capacitive loading technique was proposed by [4] by etching patch as a Sierpinski carpet of different iteration. $36.5 \%$ size reduction was achieved after the second iteration of Sierpinski carpet fractal. The present design shows more percentage size reduction when compared with the proposed design in [4-15] using Sierpinski carpet fractal iterations.

\section{ANTENNA DESIGN}

\subsection{Patch Antenna Design}

Three essential parameters are of importance when designing a rectangular patch antenna: frequency, the thickness of the substrate and dielectric material of the substrate. The antenna was designed to resonate at a frequency of $1.8 \mathrm{GHz}$ and was built on an FR-4 substrate which has a permittivity of 4.3 and thickness of $1 \mathrm{~mm}$. In analysing microstrip patch antenna, popular models employed are cavity model, full wave model and transmission line model [16]. It was reported in [16] that the transmission line models provides a good deal of physical insight and also the simplest among other models. The dimension of the patch antenna was calculated using transmission line model [16]. According to the given equation, the width of the patch can be calculated:

$$
w=\frac{c}{2 f_{o}} \sqrt{\frac{2}{\varepsilon_{r}+1}}
$$

Where $w$ represents the width of the patch, $f_{o}$ the resonant frequency, and $\varepsilon_{r}$ the relative dielectric constant.

The effective dielectric constant is obtained by:

$$
\varepsilon_{\text {reff }}=\frac{\varepsilon_{r}+1}{2}+\frac{\varepsilon_{r}-1}{2}\left(1+\frac{12 h}{w}\right)^{\frac{-1}{2}}
$$

Due to the fringing effect, the patch dimension along its length is extended on each side by a distance $\Delta L$ which is given by:

$$
\Delta L=0.412 h \frac{\left(\varepsilon_{\text {reff }}+0.3\right)(w / h+0.264)}{\left(\varepsilon_{\text {reff }}-0.258\right)\left({ }^{w} / h+0.8\right)}
$$

Where $h$ is the height of the substrate.

The actual length of the patch is given by:

$$
L=L_{\text {eff }}-2 \Delta L
$$

Where $L_{e f f}=\frac{C}{2 f_{o} \sqrt{\varepsilon_{\text {reff }}}}$ is the effective length which is also known as the electrical length of the patch antenna and its closely related to the resonant frequency. Increasing the length of the rectangular patch antenna reduces the resonant frequency.
Using the above equations and substituting the known parameters, the dimension of the patch antenna can easily be calculated.

Table 1 shows the dimensions of the proposed antenna in $(\mathrm{mm})$ using FR-4 substrate with dielectric constant of 4.3 and thickness of $1 \mathrm{~mm}$ at the centre frequency of $1.8 \mathrm{GHz}$ where $\mathrm{Wp}, \mathrm{Lp}$, Wa, Wf and Lf corresponds to width of the patch, length of the patch, distance from edge of patch to the feed point, width and length of the feed as shown in Figure 1.

\begin{tabular}{|c|c|c|c|c|c|c|}
\hline Antenna & $\begin{array}{c}\mathrm{Wp} \\
(\mathrm{mm})\end{array}$ & $\begin{array}{c}\mathrm{Lp} \\
(\mathrm{mm})\end{array}$ & $\begin{array}{c}\text { Wa } \\
(\mathrm{mm})\end{array}$ & $\begin{array}{c}\text { Wf } \\
(\mathrm{mm})\end{array}$ & $\begin{array}{c}\text { Lf } \\
(\mathrm{mm})\end{array}$ & $\begin{array}{c}\text { Area } \\
(\mathrm{mm})^{2}\end{array}$ \\
\hline $\begin{array}{l}\text { Main } \\
\text { Patch }\end{array}$ & 39 & 60 & 27 & 1.9 & 15 & 2340 \\
\hline $\begin{array}{l}1^{\text {st }} \\
\text { iteration }\end{array}$ & 33.2 & 49 & 22 & 1.9 & 15 & 1626.8 \\
\hline $\begin{array}{l}2^{\text {nd }} \\
\text { iteration }\end{array}$ & 32.7 & 49 & 21 & 1.9 & 15 & 1602.3 \\
\hline $\begin{array}{l}\text { Modified } \\
\text { approach }\end{array}$ & 31.5 & 40 & 17 & 2 & 15 & 1260 \\
\hline
\end{tabular}

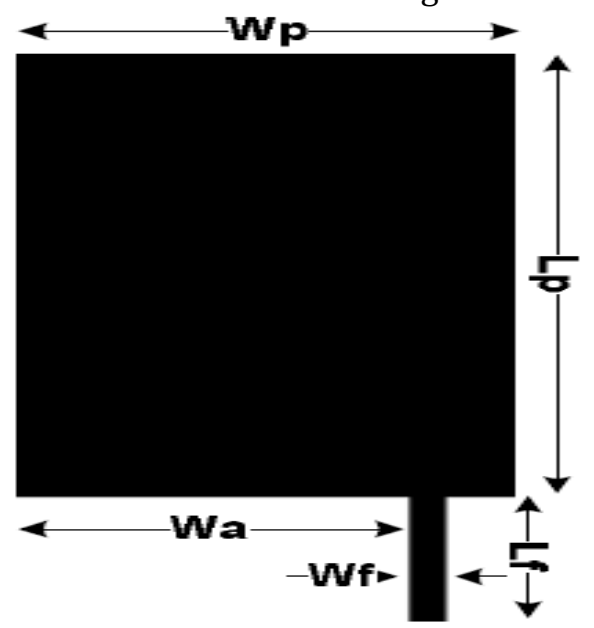

Figure 1: Edge Fed Microstrip Patch Antenna

Table 1: Edge fed Sierpinski Carpet design parameters

\subsection{Sierpinski Carpet Fractal Iteration}

Miniaturization methods on fractal antenna involve the process whereby some parts of the main patch structure has been removed. The microstrip patch antenna is etched as a Sierpinski Carpet fractal in other to obtain compact size antenna using the different order of iteration. The initial stage of Sierpinski Carpet involves dividing the rectangular patch into nine smaller congruent rectangles in which the central rectangle is removed. The remaining eight rectangles in the further iteration are divided into nine more congruent rectangles and removing the central rectangles from each rectangle. Other iterations follow the same procedure [15]. 


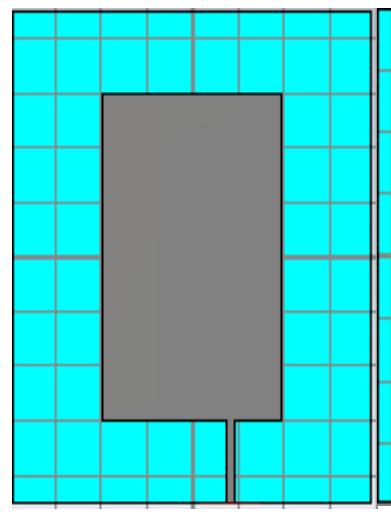

(a)

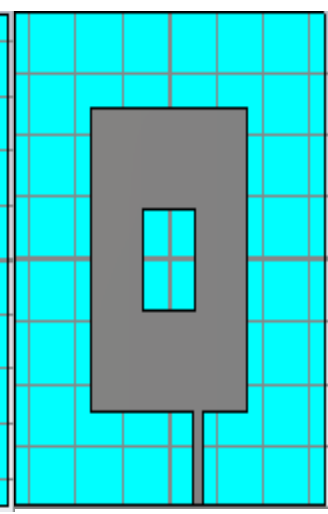

(b)

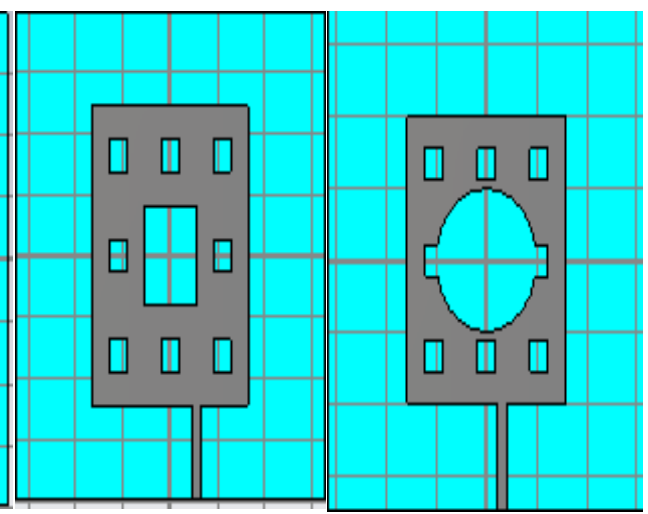

(c) (d)

Figure 2: Schematics of the designed antenna (a) Main patch (b) First iteration (c) second iteration (d) modified second iteration

\subsection{Feeding Techniques}

In feeding microstrip patch antenna, different methods could be used. Among of which includes coaxial probe, aperture coupling, proximity coupling and microstrip line feed. Microstrip line technique was used in feeding the proposed antenna due to its simplicity. The antenna has the best performance when the transmission line is placed at a point where the current does not face obstruction. The proposed antenna feed position is slightly moved away from the centre of the patch for better performance and impedance matching [15]. The schematic diagram of the proposed design showing different stages of iteration is presented in Figure 2.

\section{SIMULATION AND RESULT}

Simulation of the antenna was performed using CST microwave studio 2014. The conventional patch antenna was designed using the above mention procedure in section 2. The dimension of the patch was tabulated in Table 1. Sierpinski Carpet fractal iteration was performed up to 2nd Iteration using iteration factor of $1 / 3$. After the second iteration, the rectangular slot in the middle of the patch was replaced with a circle to achieve size reduction. To achieve $1.8 \mathrm{GHz}$ resonant frequency, parametric studies was performed to determine the optimum dimension of the patch. The radius of the circle at the middle of the proposed antenna to give optimum result was determined to be $7 \mathrm{~mm}$. Figure 2 shows the stages of the proposed antenna. With the increment in the number of iteration, it was observed that the size of the antenna decreases. The percentage size reduction from the conventional patch to the proposed antenna is shown in Table 2 .

\section{Table 2: Size Reduction}

\begin{tabular}{lcc}
\hline Antenna & Area $(\mathrm{mm})^{2}$ & Area Reduction \\
\hline Without Iteration & 2340 & \\
$1^{\text {st }}$ iteration & 1626.8 & $30.47 \%$ \\
$2^{\text {nd }}$ iteration & 1602.3 & $31.5 \%$ \\
Modified approach & 1260 & $46.15 \%$ \\
\hline
\end{tabular}

\subsection{Results}

The performance of the proposed antenna was analysed in terms of return loss, radiation pattern and gain. For the different stages of iteration, the return loss of the conventional patch, first iteration, second iteration and the modified second iteration are shown in Figures $3 a, b, c$ and d respectively. An antenna is said to be resonating when the return loss is below $10 \mathrm{~dB}$. From the tabulated result, it was seen that the entire four antennas have a better return loss less than $-15 \mathrm{~dB}$.

The radiation pattern of the main patch and other stages of iteration are shown in Figures $4 a$ to b. The Eplane with phi $=0$ degree and $\mathrm{H}$-plane with phi $=90$ degree is displayed for different value of theta. The maximum gain of each antenna is tabulated in Table 3 . From the similar pattern of radiation exhibited by the four antennas, it is verified that the iteration process on the conventional patch does not affect the antenna radiation pattern. The results show that the main patch, first iteration, second iteration and modified second iteration resonate at frequency of $1.8 \mathrm{GHz}$ with a good return loss and similar radiation pattern. 


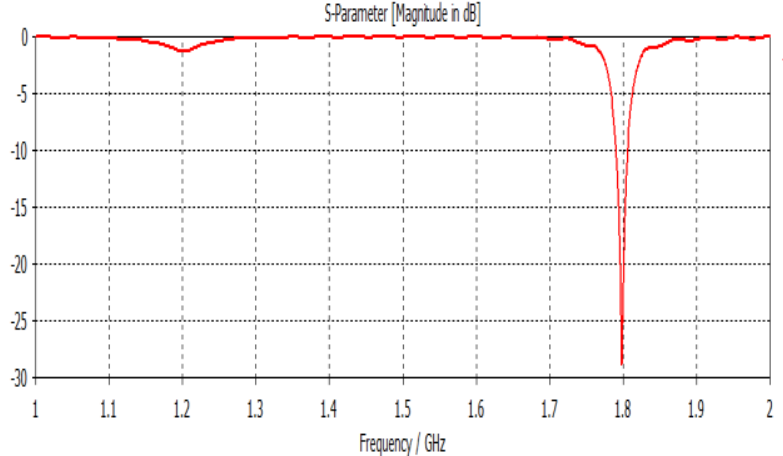

(a)

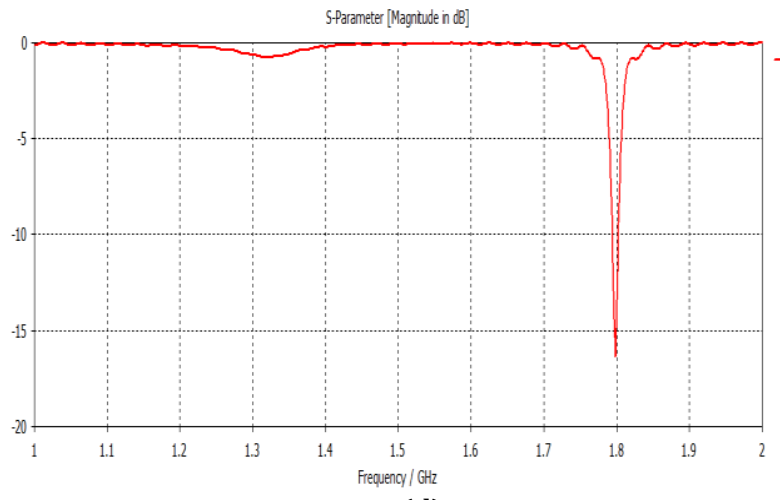

(d)

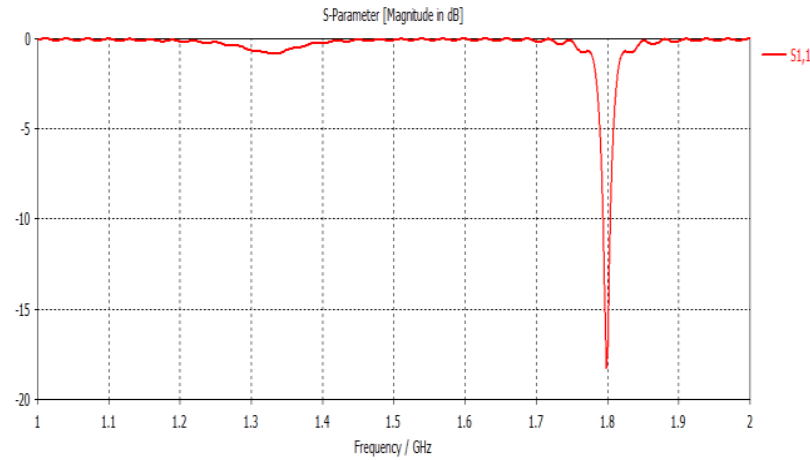

(b)

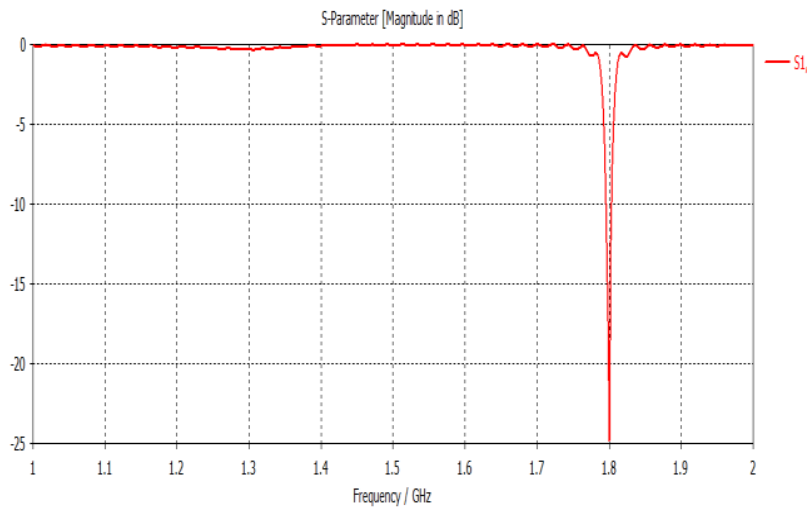

(d)

Figure 3: Simulated Return loss of (a) Main patch (b) First iteration (c) second iteration (d) modified second iteration.

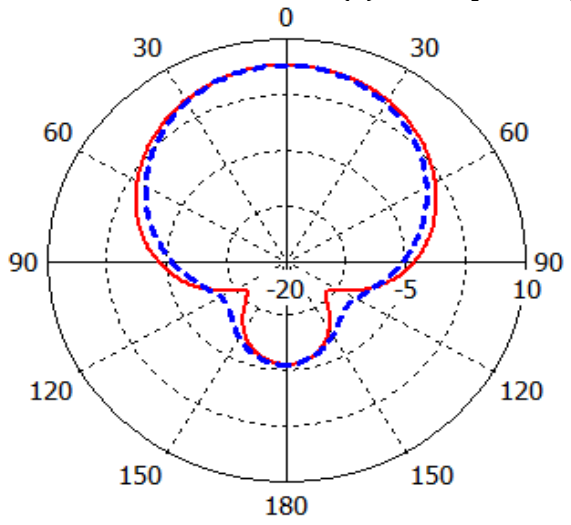

Theta / Degree vs. dB

(a)

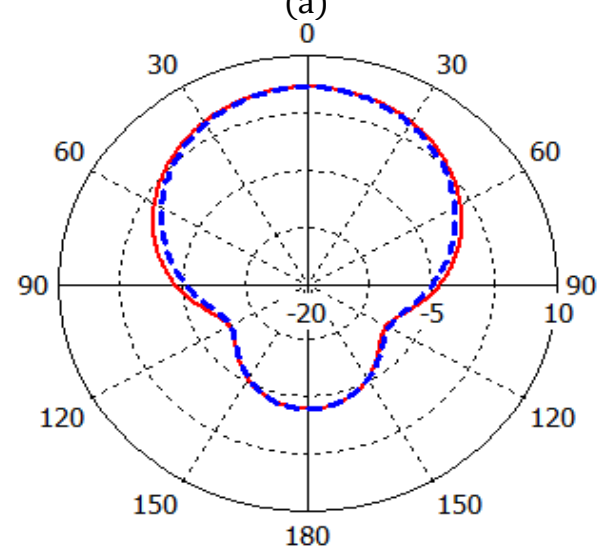

Theta / Degree vs. dB

(c)

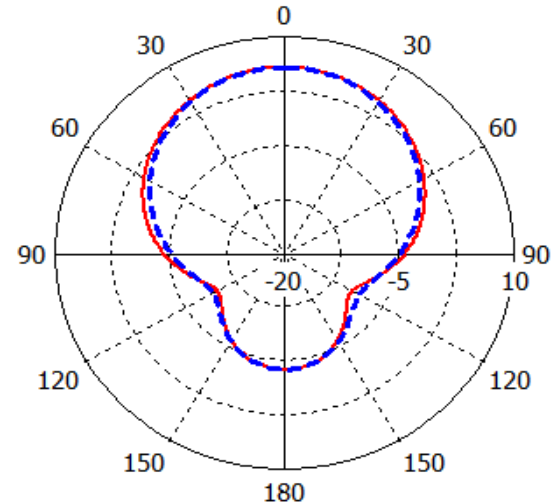

Theta / Degree vs. dB

(b)

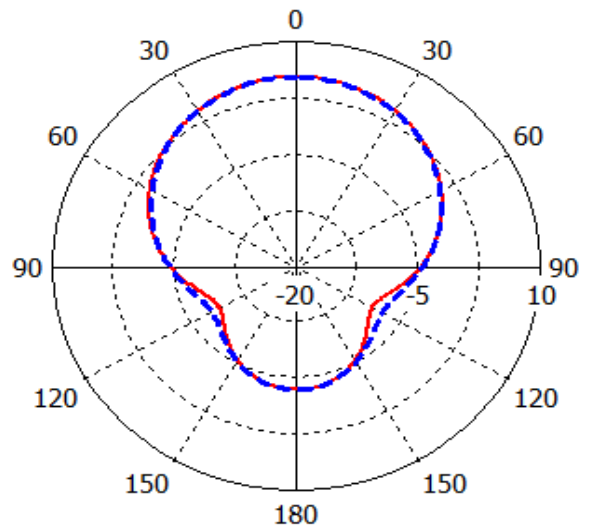

Theta / Degree vs. dB

(d)

\section{E-Plane Farfield - - - H-Plane Farfield}

Figure 4: Radiation pattern of (a) Main patch (b) First iteration (c) second iteration (d) modified second iteration 


\section{CONCLUSION}

An edge fed miniaturized patch antenna etched as Sierpinski carpet fractal was designed to resonate at 1.8 GHz. Through fractal iteration, size reduction was achieved without affecting the resonant frequency and the antenna radiation pattern. A higher percentage of size reduction was achieved as the number of iteration increase. After the second iteration, the Sierpinski carpet fractal achieved $31.5 \%$ size reduction. To further reduce the antenna size, second iteration Sierpinski carpet fractal was modified by replacing the rectangular slot in the middle of the patch with a circular slot to achieve further size reduction. The proposed antenna which was simulated using CST studio achieved $46.15 \%$ size reduction.

\section{REFERENCES}

[1] Wong, K. L. Compact and Broadband Microstrip Antennas, John Wiley \& Sons Inc., 2002.

[2] Herscovici, N., Osorio, M. F. and Peixerio, C. "Miniaturization of rectangular microstrip Patches using genetic algorithms," IEEE Antennas and Wireless Propagation Letters, vol. 1, pp. 94- 97, 2002.

[3] Lo, T. K and Hwang, Y. "Microstrip antennas of very high permittivity for personal communications," Asia-Pacific Microwave Conference, 1997, pp. 253256.

[4] Chen, W and Wang, G. M. "Small Size Edge-Fed Sierpinski Carpet Microstrip Patch Antenna," Progress in Electromagnetics Researches, vol. 3, 2008, pp. 195-202.

[5] Ooi, B. L. "A modified contour integral analysis for Sierpinski fractal carpet antennas with and without electromagnetic band gap ground plane," IEEE Trans. Antennas and Propagation, vol. 52, no. 1, 2004, pp. 1286-1293.

[6] Anguera, J., Martínez, E., Puente, C., Borja, C and Soler, J. "Broad-Band Dual-Frequency Microstrip Patch Antenna with Modified Sierpinski Fractal Geometry," IEEE Trans. Antennas and Propagation, vol. 52, no. 1, January 2004.
[7] Mishra, R., Ghatak, R and Poddar, D. "Design formula for sierpinski gasket pre fractal planar monopole antennas," IEEE Antennas and Propagation Magazine, vol. 50, no.3, 2008, pp. 104-107.

[8] Chen, L., Chang, Y and Xie, H. "Minkowski fractal patch antenna for size and radar cross section reduction," IEEE CIE International Conference, vol. 2, 2011, pp. 1406-1409.

[9] Younas, A. "A new directivity fractal antenna based on modified Koch snowflake geometry," Asia-Pacific Microwave Conference Proceedings (APMC), pp. 191-194, 2010.

[10] Yo, T. C., Lee, C. M., Hsu, C. M and Luo, C. H. “Compact circularly polarized rectenna with unbalanced circular slots," IEEE Transactions on Antennas and Propagation, vol. 56, no. 3, 2008, pp. 882-886.

[11] Ali, J. K. "A new compact size microstrip patch antenna with irregular slot for handheld GPS application," Engineering and Technology, vol. 26, no. 10, 2008.

[12] Vera, G. A., Georgidis, A., Collado, A and Via, S. "Design of $2.45 \mathrm{GHz}$ rectenna for electromagnetic (EM) energy scavenging," Proceedings of the $34^{\text {th }}$ European Microwave Conference, vol. 1, October 2004, pp. 125-128.

[13] Yu, Z. W., Wang, G. M., Gao, X. J and Lu, K. "A novel small size single patch microstrip antenna based on Koch and Sierpinski fractal shapes," Progress in Electromagnetic Research Letters, vol. 17, 2010, pp. 95-103.

[14] Gianviffwb, J. P and Yahya, R. S. "Fractal antennas: A novel antenna miniaturization technique and applications," IEEE Antennas and Propagation Magazine, vol. 44, no. 1, 2002, pp. 20-36.

[15] Shrestha, S., Park, J. J., Nouh, S. K and Choi, D. Y. "Design of $2.45 \mathrm{GHz}$ Sierpinski Fractal Based Miniaturized Microstrip Patch Antenna" IEEE 18th Asia-Pacific Conference on Communications (APCC), 2012, pp. 36-41.

[16] Balanis, C. A. Antenna Theory: Analysis and Design, 3rd ed. New York: Wiley-Interscience, 2005. 